\title{
Instantaneous Deteriorated Economic Order Quantity (EOQ) Model with Promotional Effort Cost
}

\author{
Padmabati Gahan ${ }^{1}$, Sourav Dhal ${ }^{2}$, Monalisha Pattnaik ${ }^{3 *}$ \\ ${ }^{1,3}$ Dept. of Business Administration, Sambalpur University, Jyotivihar, Sambalpur, India \\ ${ }^{2}$ Cluster Supply Planner, Hindustan Coca Cola Beverage Pvt. Ltd., Bengaluru, Karnataka, India
}

\begin{abstract}
This model studies the problem by proposing a continuous review inventory model under promotion by assuming that the units do not lost due to deterioration of the items. In this model optimization has been studied for applying promotional effort cost with promotion constraint. The effect of deteriorating items on the instantaneous profit maximization replenishment model under promotion is considered in this model. The market demand may increase with the promotion of the product over time when the units do not lost due to deterioration. In this model, promotional effort and replenishment decision are adjusted arbitrarily upward or downward for profit maximization model in response to the change in market demand within the planning horizon with fixed ordering cost. The objective of this model is to determine the optimal time length, the promotional effort and the replenishment quantity with fixed ordering cost so that the net profit is maximized and the numerical analysis show that an appropriate promotion policy can benefit the retailer and that promotion policy is important, especially for deteriorating items. Finally, sensitivity analyses of the optimal solution with respect to the major parameters are also studied to draw the managerial implications.
\end{abstract}

Keywords - Instantaneous production, Promotional effort cost, Deteriorated items, Profit maximization model.

\section{INTRODUCTION}

Inventory management plays a significant role in businesses since it can help the companies to reach the goal ensuring prompt delivery, avoiding shortages, helping sales at competitive prices with cost effective and efficiency. Inventory management is one of the most important components of the production function where the production function is the mid between procurement function and physical distribution function. Since inventory management is the key factor of the production function so, the success of inventory management is the key to the success of production system in a company. The mission of inventory management are the right quality, the right quantity, the right condition, the right cost tradeoffs, the right customer, the right information, the right response, the right time, the right value, the right product and the right place. The mathematical modeling of real-world inventory problems necessitates the simplification of assumptions to make the mathematics flexible. However, excessive simplification of assumptions results in mathematical models that do not represent the inventory situation to be analyzed. Many models have been proposed to deal with a variety of inventory problems. The classical analysis of inventory control considers three costs for holding inventories. These costs are the ordering cost, carrying cost and shortage cost. The classical analysis builds a model of an inventory system and calculates the EOQ which minimize these three costs so that their sum is satisfying minimization criterion. One of the unrealistic assumptions is that items stocked preserve their physical characteristics during their stay in inventory. Items in stock are subject to many possible risks, e.g. damage, spoilage, dryness; vaporization etc., those results decrease of usefulness of the original one and a cost is incurred to account for such risks. To control an inventory system, one cannot be ignored demand since inventory is partially determined by demand, as suggested by Waters (1994) and Osteryoung, Mc Carty and Reinhart (1986) in many cases a small change in the demand pattern may result in a large change in optimal inventory decisions. A manager of a company has to investigate the factors that influence demand pattern, because customers' purchasing behavior may be affected by factors such as promotional effort, units lost due to deterioration, quantity ordered, profit and so on. A subject in the area of inventory theory that has recently been receiving considerable attention is the class of inventory models with deterioration. With these models, the presence 
of retail inventory is assumed to have a motivating effect on the customer.

Many models have been proposed to deal with a variety of inventory problems. Comprehensive reviews of inventory models can be found in Rafaat (1991) and Jain and Silver (1994). Pattnaik (2012) derived some deterministic inventory models, which are developed under the assumption that demand is either constant or stock dependent for deteriorated items. Bose, Goswami and Chaudhuri (1995) dealt with the EOQ problem for deteriorating items with linear time dependent demand rate under inflation where shortages and discounts are allowed. Goyal and Gunasekaran (1995) considered the effect of different market policies, e.g. the price per product and advertisement frequency on the demand of a perishable item. Gupta and Gerchak (1995) analyzed two scenarios; the first considers TOD as a constant and the store manager may choose an appropriate value, while the second assumes that TOD is a random variable. Hariga (1995) proposed the correct theory for the problem supplied with numerical examples. The most recent work found in the literature is that of Hariga (1996) who extended his earlier work by assuming a time-varying demand over a finite planning horizon. Padmabhan and Vrat (1995) presented an EOQ inventory model for perishable items with a stock dependent selling rate. Unlike the work of Wee (1993) who studied the case of partial backlogging for deteriorating items, Salameh, Jaber and Noueihed (1999) studied an EOQ inventory model in which it assumes that the percentage of on-hand inventory wasted due to deterioration is a characteristic feature of the inventory conditions which govern the item stocked.

Furthermore, retailer promotional activity has become more and more common in today's business world. For example, Wall Mart and Costco often try to stimulate demand for specific types of electric equipment by offering price discounts; clothiers Baleno and NET make shelf space for specific clothes items available for longer periods; McDonald's and Burger King often use coupons to attract consumers. Other promotional strategies include free goods, advertising, and displays and so on. The promotion policy is very important for the retailer. How much promotional effort the retailer makes has a big impact on annual profit. Residual costs may be incurred by too many promotions while too few may result in lower sales revenue. Tsao and Sheen (2008) discussed dynamic pricing, promotion and replenishment policies for a deteriorating item under permissible delay in payment. Hariga (1994) studied the effects of inflation and time value of money on the replenishment policies of items with time continuous nonstationary demand over a finite planning horizon.

This study addresses the problem by proposing a continuous review inventory model under promotion by assuming that the units do not lost due to deterioration of the items. In this model optimization has been studied for applying promotional effort cost with promotion constraint. The effect of deteriorating items on the instantaneous profit maximization replenishment model under promotion is considered in this model. The market demand may increase with the promotion of the product over time when the units do not lost due to deterioration. In the existing literature about promotion it is assumed that the promotional effort cost is a function of promotion. Tripathy and Pattnaik (2008, 2011) studies profit maximization entropic order quantity model for deteriorated items with stock dependent demand where discounts are allowed for acquiring more profit. In this model, promotional effort and replenishment decision are adjusted arbitrarily upward or downward for profit maximization model in response to the change in market demand within the planning horizon. The objective of this model is to determine optimal promotional efforts and replenishment quantities in an instantaneous replenishment profit maximization model.

All mentioned above inventory literatures with deterioration or no wasting the percentage of on-hand inventory due to deterioration have the basic assumptions that the retailer owns a storage room with optimal order quantity. In recent years, companies have started to recognize that a tradeoff exists between product varieties in terms of quality of the product for running in the market smoothly. In the absence of a proper quantitative model to measure the effect of product quality of the product, these companies have mainly relied on qualitative judgment. This model postulates that measuring the behavior of production systems may be achievable by incorporating the idea of retailer in making optimum decision on replenishment of traditional model. The major assumptions used in the above research articles are summarized in Table 1. 
Table.1: Summary of the Related Researches

\begin{tabular}{|c|c|c|c|c|c|c|c|c|}
\hline $\begin{array}{l}\text { Author(s) } \\
\text { and } \\
\text { published } \\
\text { Year }\end{array}$ & $\begin{array}{c}\text { Structure } \\
\text { of the } \\
\text { model }\end{array}$ & Demand & $\begin{array}{l}\text { Demand } \\
\text { patterns }\end{array}$ & Deterioration & $\begin{array}{c}\text { Promotional } \\
\text { effort cost }\end{array}$ & Planning & $\begin{array}{c}\text { Units Lost } \\
\text { due } \\
\text { Deterioration }\end{array}$ & Model \\
\hline $\begin{array}{l}\text { Hariga } \\
\text { (1994) }\end{array}$ & $\begin{array}{l}\text { Crisp } \\
\text { (EOQ) }\end{array}$ & Time & $\begin{array}{c}\text { Non- } \\
\text { stationary }\end{array}$ & Yes & No & Finite & No & Cost \\
\hline $\begin{array}{l}\text { Tsao et al. } \\
\text { (2008) }\end{array}$ & $\begin{array}{l}\text { Crisp } \\
\text { (EOQ) }\end{array}$ & Time and Price & $\begin{array}{l}\text { Linear and } \\
\text { Decreasing }\end{array}$ & Yes & Yes & Finite & No & Profit \\
\hline $\begin{array}{l}\text { Pattnaik } \\
(2009)\end{array}$ & $\begin{array}{c}\text { Crisp } \\
(\text { EnOQ })\end{array}$ & $\begin{array}{c}\text { Constant } \\
\text { (Deterministic) }\end{array}$ & Constant & $\begin{array}{c}\text { Yes } \\
\text { (Instant) }\end{array}$ & No & Finite & No & Profit \\
\hline $\begin{array}{l}\text { Pattnaik } \\
(2011)\end{array}$ & $\begin{array}{l}\text { Crisp } \\
\text { (EOQ) }\end{array}$ & $\begin{array}{c}\text { Constant } \\
\text { (Deterministic) }\end{array}$ & Constant & $\begin{array}{c}\text { Yes } \\
\text { (Instant) }\end{array}$ & No & Finite & No & Profit \\
\hline $\begin{array}{l}\text { Salameh } \\
\text { et al. } \\
(1993)\end{array}$ & $\begin{array}{l}\text { Crisp } \\
\text { (EOQ) }\end{array}$ & $\begin{array}{c}\text { Constant } \\
\text { (Deterministic) }\end{array}$ & Constant & Yes & No & Finite & Yes & Profit \\
\hline $\begin{array}{c}\text { Present } \\
\text { model } \\
(2017)\end{array}$ & $\begin{array}{l}\text { Crisp } \\
\text { (EOQ) }\end{array}$ & $\begin{array}{c}\text { Constant } \\
\text { (Deterministic) }\end{array}$ & Constant & $\begin{array}{c}\text { Yes } \\
\text { (Wasting) }\end{array}$ & Yes & Finite & No & Profit \\
\hline
\end{tabular}

The remainder of the model is organized as follows. In Section 2 assumptions and notations are provided for the development of the model. The mathematical formulation is developed in Section 3. The solution procedure is given in Section 4. In Section 5, numerical example is presented to illustrate the development of the model. The sensitivity analysis is carried out in Section 6 to observe the changes in the optimal solution. Finally in Section 7 the summary and the concluding remarks are explained.

\section{ASSUMPTIONS AND NOTATIONS}

r Consumption rate,

$t_{c} \quad$ Cycle length,

h Holding cost of one unit for one unit of time,

HC (q) Holding cost per cycle,

c Purchasing cost per unit,

$\mathrm{P}_{\mathrm{s}} \quad$ Selling Price per unit,

$\alpha \quad$ Percentage of on-hand inventory that is lost due to deterioration,

q Order quantity,

$K \quad$ Ordering cost per cycle,

$q^{*} \quad$ Traditional economic ordering quantity (EOQ),

$\rho \quad$ The promotional effort per cycle

PE $(\rho)$ The promotional effort cost, PE $(\rho)=K_{1}(\rho-1)^{2} r^{\alpha_{1}}$, where $\mathrm{K}_{1}>0$ and $\alpha_{1}$ is a constant

$\varphi(\mathrm{t}) \quad$ On-hand inventory level at time $\mathrm{t}$,

$\pi_{1}(q, \rho)$ Net profit per unit of producing q units per cycle in crisp strategy, $\pi(\mathrm{q}, \rho) \quad$ Average profit per unit of producing $\mathrm{q}$ units per cycle in crisp strategy,

\section{MATHEMATICAL MODEL}

Denote $\varphi(t)$ as the on-hand inventory level at time t. During a change in time from point $t$ to $t+d t$, where $t+d t>t$, the on-hand inventory drops from $\varphi(t)$ to $\varphi(t+d t)$. Then $\varphi(t+d t)$ is given as:

$\varphi(\mathrm{t}+\mathrm{dt})=\varphi(\mathrm{t})-\mathrm{r} \rho \mathrm{dt}-\alpha \varphi(\mathrm{t}) \mathrm{dt}$

Equation $\varphi(\mathrm{t}+\mathrm{dt})$ can be re-written as: $\frac{\varphi(\mathrm{t}+\mathrm{dt})-\varphi(\mathrm{t})}{d t}=-r \rho-$ $\alpha \varphi(\mathrm{t})$

and $\mathrm{dt} \rightarrow 0$, equation $\frac{\varphi(\mathrm{t}+\mathrm{dt})-\varphi(\mathrm{t})}{d t}$ reduces to: $\frac{\mathrm{d} \varphi(\mathrm{t})}{d t}+\alpha \varphi(\mathrm{t})$

$+\mathrm{r} \rho=0$

It is a differential equation, solution is

$\varphi(\mathrm{t})=\frac{-\mathrm{r} \rho}{\alpha}+\left(\mathrm{q}+\frac{\mathrm{r} \rho}{\alpha}\right) \times \mathrm{e}^{-\alpha \mathrm{t}}$

Where $\mathrm{q}$ is the order quantity which is instantaneously replenished at the beginning of each cycle of length $t_{c}$ units of time. The stock is replenished by q units each time these units are totally depleted as a result of outside demand and deterioration. Behavior of the inventory level for the above model is illustrated in Fig. 1. The cycle length, $t_{c}$, is determined by first substituting $t_{c}$ into equation $\varphi(t)$ and then setting it equal to zero to get: $\mathrm{t}_{\mathrm{c}}=\frac{1}{\alpha} \ln \left(\frac{\alpha \mathrm{q}+\mathrm{r} \rho}{\mathrm{r} \rho}\right)$ 


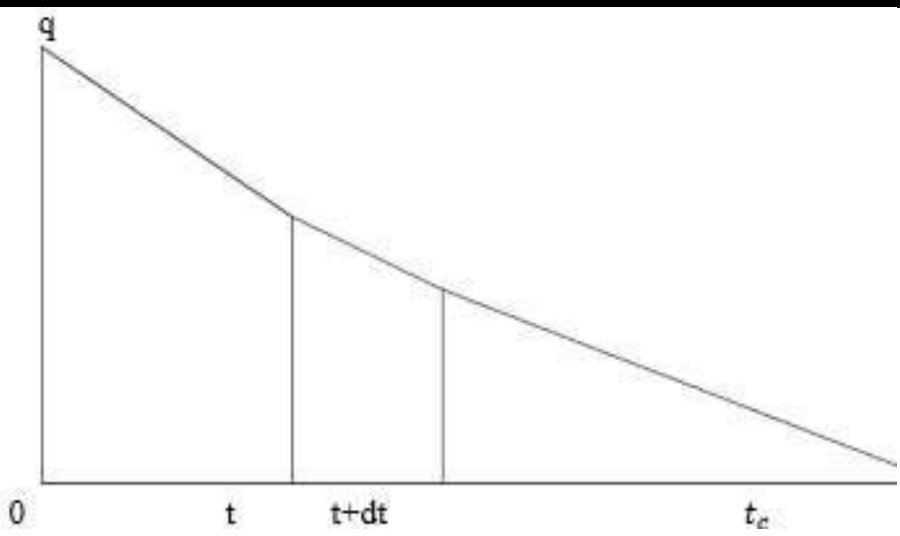

Fig.1: Behavior of the Inventory over a Cycle for a

\section{Deteriorating Item}

Equation $\varphi(t)$ and $t_{c}$ are used to develop the mathematical model. It is worthy to mention that as $\alpha$ approaches to zero, $t_{c}$ approaches to $\frac{\mathrm{q}}{\mathrm{r} \rho}$. The total cost per cycle, TC $(\mathrm{q}, \rho)$ is the sum of the procurement cost per cycle, $\mathrm{K}+\mathrm{cq}$ and the holding cost per cycle, $\mathrm{HC}(\mathrm{q}, \rho)$. $\mathrm{HC}(\mathrm{q}, \rho)$ is obtained from the equation $\varphi(t)$ as:

$$
\begin{aligned}
H C(q, \rho) & =\int_{0}^{t c} h \varphi(t) d t \quad=h \int_{0}^{\frac{1}{\alpha} \ln \left(\frac{\alpha \mathrm{q}+\mathrm{r} \rho}{\mathrm{r} \rho}\right)}\left[-\frac{\mathrm{r} \rho}{\alpha}+\right. \\
\left(\mathrm{q}+\frac{\mathrm{r} \rho}{\alpha}\right) & \left.\times \mathrm{e}^{-\alpha \mathrm{t}}\right] d t \\
= & h \times\left[\frac{q}{\alpha}-\frac{r \rho}{\alpha^{2}} \ln \left(\frac{\alpha q+r \rho}{r \rho}\right)\right]
\end{aligned}
$$

$\operatorname{PE}(\rho)=K_{1}(\rho-1)^{2} r^{\alpha_{1}}$

$\mathrm{TC} \quad(\mathrm{q}, \quad \rho)=K+c q+h \times\left[\frac{q}{\alpha}-\frac{r \rho}{\alpha^{2}} \times \ln \left(\frac{\alpha q+r \rho}{r \rho}\right)\right]+$ $K_{1}(\rho-1)^{2} r^{\alpha_{1}}$

The total cost per unit of time, $\operatorname{TCU}(\mathrm{q}, \rho)$, is given by dividing equation TC $(\mathrm{q}, \rho)$ by equation $\mathrm{t}_{\mathrm{c}}$ to give: TCU $(\mathrm{q}$, $\rho)=$

$\left[K+\mathrm{cq}+h \times\left[\frac{q}{\alpha}-\frac{r \rho}{\alpha^{2}} \ln \left(\frac{\alpha q+r \rho}{r \rho}\right)\right]+K_{1}(\rho-1)^{2} r^{\alpha_{1}}\right] \times$

$\left[\frac{1}{\alpha} \ln \left(\frac{\propto \mathrm{q}+\mathrm{r} \rho}{\mathrm{r} \rho}\right)\right]^{-1}$

$=\frac{K \propto+(c \propto+h) q+K_{1}(\rho-1)^{2} r^{\alpha_{1}}}{\ln \left(1+\frac{\alpha q}{r \rho}\right)}-\frac{h r \rho}{\alpha}$

As $\alpha$ approaches zero in equation $\operatorname{TCU}(\mathrm{q}, \rho)$ reduces to $\operatorname{TCU}(\mathrm{q}, \rho)=\frac{K r \rho}{q}+\operatorname{cr} \rho+\frac{h q}{2}+K_{1}(\rho-1)^{2} r^{\alpha_{1}}$ and TC $(\mathrm{q}$, $\rho)=K+c q+\frac{h q^{2}}{2 r \rho}+K_{1}(\rho-1)^{2} r^{\alpha_{1}} \quad$ whose solution is given by the traditional EOQ formula, $q^{*}=\sqrt{\frac{2 K r \rho}{h}}$. The total profit per cycle is $\pi_{1}(\mathrm{q}, \rho)$.

$\pi_{1}(q, \rho)=q \times P_{s}-T C(q, \rho)=\left(q \times P_{s}\right)-K-c q-\frac{h q^{2}}{2 r \rho}-$ $K_{1}(\rho-1)^{2} r^{\alpha_{1}}$ where, TC $(\mathrm{q}, \rho)$ the total cost per cycle. The average profit $\pi(\mathrm{q}, \rho)$ per unit time is obtained by dividing $\mathrm{t}_{\mathrm{c}}$ in $\pi_{1}(\mathrm{q}, \rho)$. Hence the profit maximization problem is:

Maximize $\pi_{1}(\mathrm{q}, \rho)$

$\forall q \geq 0, \rho \geq 0$

\section{OPTIMIZATION}

The optimal ordering quantity $q$ per cycle can be determined by differentiating equation $\pi_{1}(q, \rho)$ with respect to $\mathrm{q}$, then setting these to zero.

In order to show the uniqueness of the solution in, it is sufficient to show that the net profit function throughout the cycle is concave in terms of ordering quantity q. The second order derivates of the equation $\pi_{1}(q, \rho)$ with respect to q are strictly negative. Consider the following propositions.

Proposition 1 The net profit $\pi_{1}(q, \rho)$ per cycle is concave downward or convex upward in $\mathrm{q}$. Conditions for optimal $\mathrm{q}$ is

$\frac{d \pi_{1}(q)}{d q}=P_{s}-c-\left(\frac{h q}{r \rho}\right)=0$

The second order derivative of the net profit per cycle with respect to q can be expressed as: $\frac{d^{2} \pi_{1}(q)}{d q^{2}}=-\frac{h}{r \rho}$

Since, $r>0, \rho>0$ and $h>0, \frac{d^{2} \pi_{1}(q)}{d q^{2}}$ is negative.

It shows that the second order derivative of the equation $\pi_{1}(q, \rho)$ with respect to $\mathrm{q}$ is strictly negative.

Proposition 2 The net profit $\pi_{1}(q, \rho)$ per cycle is concave in $\rho$.

Conditions for optimal $\rho \frac{\partial \pi_{1}(q, \rho)}{\partial \rho}=\left(\frac{h q^{2}}{2 r \rho^{2}}\right)-2 K_{1}(\rho-$ 1) $r^{\alpha 1}=0$

The second order partial derivative of the net profit per cycle with respect to $\rho$ is

$\frac{\partial^{2} \pi_{1}(q, \rho)}{\partial q^{2}}=-\left[\frac{h q^{2}}{r \rho^{3}}+2 K_{1} r^{\alpha 1}\right]$. Since $K_{1}>0, \rho>0, r>0$ and $\mathrm{h}>0$, hence $\frac{\partial^{2} \pi_{1}(q, \rho)}{\partial q^{2}}$ is negative.

Propositions 1 and 2 show that the second partial derivatives of equation $\pi_{1}(q, \rho)$ with respect to $q$ and $\rho$ separately are strictly negative. The next step is to check that the determinant of the Hessian matrix is positive, i.e.

$\frac{\partial^{2} \pi_{1}(q, \rho)}{\partial q^{2}} \times \frac{\partial^{2} \pi_{1}(q, \rho)}{\partial \rho^{2}}-\left(\frac{\partial^{2} \pi_{1}(q, \rho)}{\partial q \partial \rho}\right)^{2}>0$ $\left(\frac{\partial^{2} \pi_{1}(q, \rho)}{\partial q^{2}}\right)$ and $\left(\frac{\partial^{2} \pi_{1}(q, \rho)}{\partial \rho^{2}}\right)$ are derived and $\frac{\partial^{2} \pi_{1}(q, \rho)}{\partial q \partial \rho}=$ $\frac{\partial^{2} \pi_{1}(q, \rho)}{\partial \rho \partial q}=\frac{h q}{r \rho^{2}}$

Hence the Hessian matrix is $\frac{2 h K_{1} r^{\alpha_{1}-1}}{\rho}>0$. 
The objective is to determine the optimal values of $\mathrm{q}$ to maximize the unit profit function of $\pi_{1}(q, \rho)$. It is very difficult to derive the optimal values of $\mathrm{q}$, hence unit profit function. There are several methods to cope with constraints optimization problem numerically. But here LINGO 13.0 software is used to derive the optimal values of the decision variable.

\section{NUMERICAL EXAMPLE}

Consider an inventory situation where $\mathrm{K}$ is Rs. 200 per order, $\mathrm{h}$ is Rs. 5 per unit per unit of time, $\mathrm{r}$ is 1000 units per unit of time, c is Rs. 100 per unit, the selling price per unit
$\mathrm{P}_{\mathrm{s}}$ is Rs. $125, \alpha$ is $0 \%, K_{1}=2.0$ and $\alpha_{1}=1.0$. The optimal solution that maximizes $\pi_{1}(q, \rho), q^{*}$ and $\rho^{*}$ are determined by using LINGO 13.0 version software and the results are tabulated in Table 2. Fig. 2 represents two dimensional plotting of promotional effort factor $\rho$ and promotional effort cost PE. Fig. 3 is the three dimensional mesh plot of order quantity q, cycle length $t_{c}$ and net profit per cycle $\pi_{1}$. Fig. 4 is the sensitivity plotting of cycle length $t_{c}$, order quantity q and net profit per cycle $\pi_{1}(q, \rho)$.

The optimal solution that maximizes $\pi_{1}(q, \rho)$ and $q^{*}$ are determined by using LINGO 13.0 version software and the results are tabulated in Table 2 .

Table.2: Optimal Values of the Proposed Model

\begin{tabular}{|c|c|c|c|c|c|c|c|}
\hline Model & Iteration & $\boldsymbol{t}^{*}$ & $\boldsymbol{\rho}^{*}$ & $\boldsymbol{q}^{*}$ & PE & $\boldsymbol{\pi}_{\mathbf{1}}(\boldsymbol{q}, \rho)$ & $\boldsymbol{\pi}(\boldsymbol{q}, \rho)$ \\
\hline Crisp & 84 & 5 & 16.625 & 83125 & 488281.2 & 550581.2 & 110116.2 \\
\hline
\end{tabular}

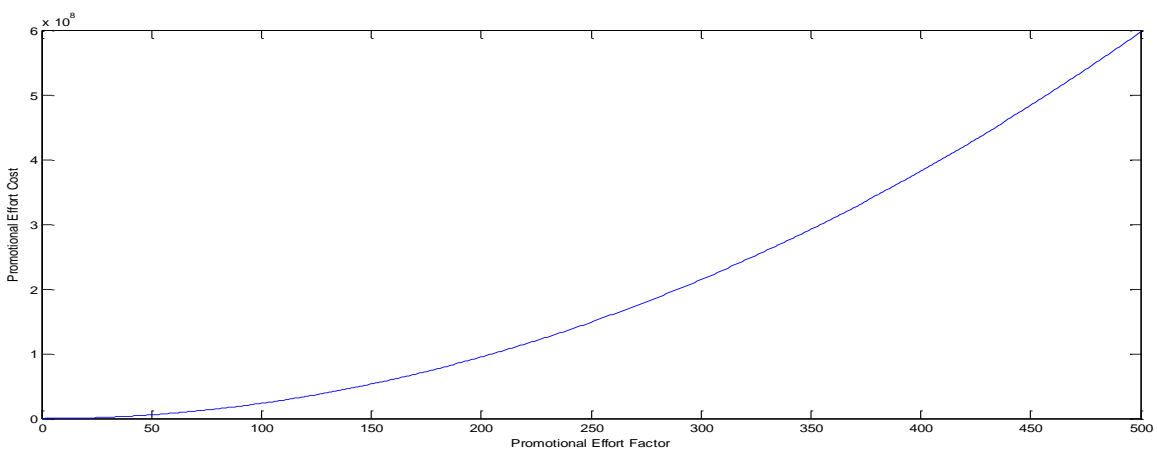

Fig.2: Two Dimensional Plotting of Promotional Effort Factor $\rho$ and Promotional Effort Cost PE

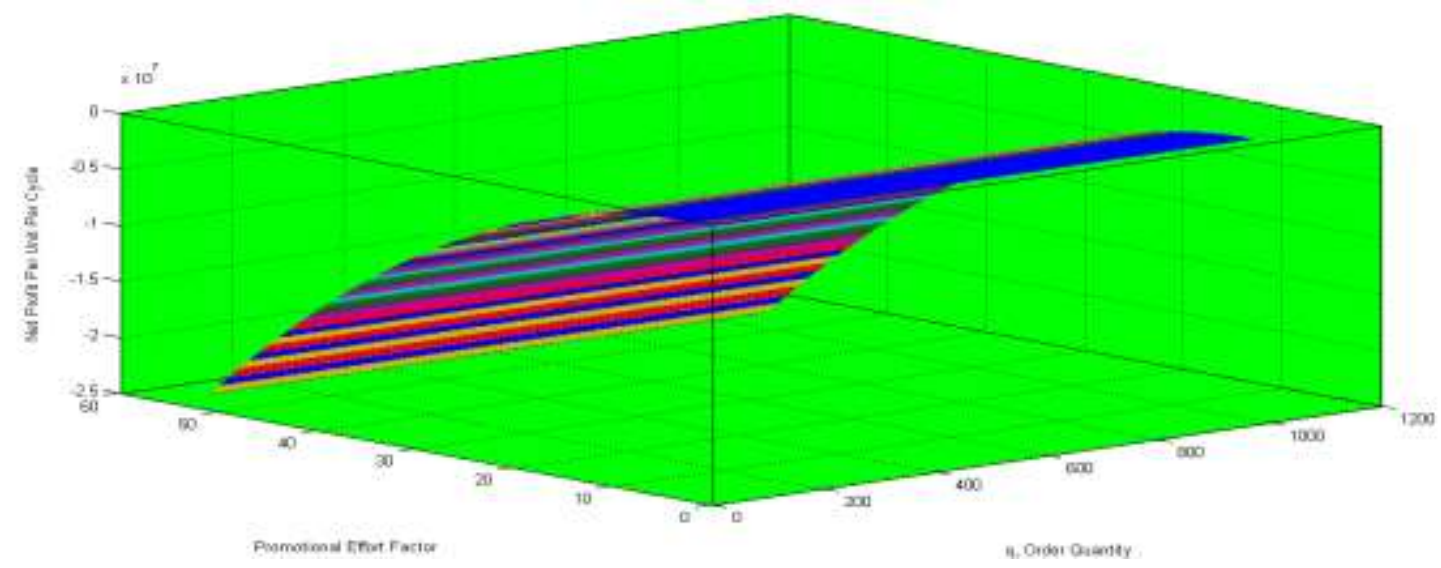

Fig.3: Three Dimensional Mesh Plotting of Order Quantity $q$, Promotional Effort Factor $\rho$ and Net Profit per Cycle $\pi_{1}(q, \rho)$ 


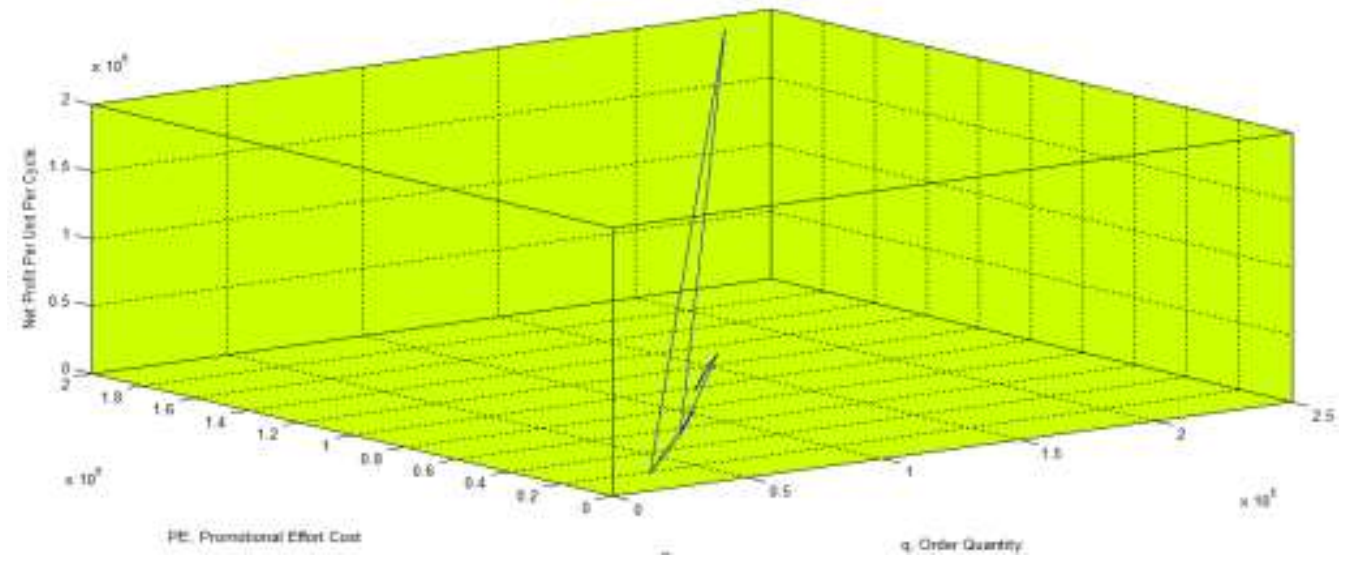

Fig.4: Sensitivity Plotting of Order Quantity q, Promotional Effort Cost PE and Net Profit per Cycle $\pi_{1}(q, \rho)$

\section{SENSITIVITY ANALYSIS}

It is interesting to investigate the influence of the major parameters $\mathrm{K}, \mathrm{h}, \mathrm{r}, \mathrm{c}$ and $P_{S}$ retailer's behavior. The computational results shown in Table 3 indicate the following managerial phenomena:

- $t_{c}$ the replenishment cycle length, $\mathrm{q}$ the optimal replenishment quantity, $\rho$ the promotional effort factor, PE promotional effort cost, $\pi_{1}$ the optimal net profit per unit per cycle and $\pi$ the optimal average profit per unit per cycle are insensitive to the parameter $\mathrm{K}$.

- $t_{c}$ the replenishment cycle length, $\mathrm{q}$ the optimal replenishment quantity, $\rho$ the promotional effort factor, PE promotional effort cost, $\pi_{1}$ the optimal net profit per unit per cycle and $\pi$ the optimal average profit per unit per cycle are moderately sensitive to the parameter h.
- $\mathrm{q}$ the optimal replenishment quantity, PE promotional effort cost, $\pi_{1}$ the optimal net profit per unit per cycle and $\pi$ the optimal average profit per unit per cycle are sensitive to the parameter $\mathrm{r}$ but $t_{c}$ the replenishment cycle length and $\rho$ the promotional effort factor is insensitive to the parameter $r$.

- $t_{c}$ the replenishment cycle length, $\mathrm{q}$ the optimal replenishment quantity, $\rho$ the promotional effort factor, PE promotional effort cost, $\pi_{1}$ the optimal net profit per unit per cycle and $\pi$ the optimal average profit per unit per cycle are insensitive to the parameter $\mathrm{c}$.

- $t_{c}$ the replenishment cycle length, $\mathrm{q}$ the optimal replenishment quantity, $\rho$ the promotional effort factor, PE promotional effort cost, $\pi_{1}$ the optimal net profit per unit per cycle and $\pi$ the optimal average profit per unit per cycle are insensitive to the parameter $P_{S}$.

Table.3: Sensitivity Analyses of the parameters $K, h, r, c$ and $P_{s}$

\begin{tabular}{|c|c|c|c|c|c|c|c|c|c|}
\hline Parameter & Value & Iteration & $\boldsymbol{t}^{*}$ & $\overline{q^{*}}$ & $\boldsymbol{\rho}^{*}$ & $\overline{\mathbf{P E}}$ & $\pi_{1}(q, \rho)$ & $\pi(\boldsymbol{q}, \rho)$ & $\begin{array}{l}\text { \% Change } \\
\text { in } \pi_{1}(q, \rho)\end{array}$ \\
\hline \multirow{3}{*}{ K } & 201 & 88 & 5 & 83125 & 16.63 & 488281.2 & 550580.2 & 110116.0 & 0.00018 \\
\hline & 205 & 82 & 5 & 83125 & 16.63 & 488281.2 & 550576.2 & 110115.2 & 0.00091 \\
\hline & 208 & 87 & 5 & 83125 & 16.63 & 488281.3 & 550573.3 & 110114.6 & 0.00143 \\
\hline \multirow{3}{*}{ h } & 5.1 & 95 & 4.90 & 79993.27 & 16.32 & 469320.7 & 530395.2 & 108200.6 & 3.66631 \\
\hline & 5.2 & 87 & 4.81 & 77038.65 & 16.02 & 451443.5 & 511339.6 & 106358.6 & 7.12730 \\
\hline & 5.5 & 95 & 4.55 & 69111.57 & 15.20 & 403538.2 & 406156.4 & 101234.4 & 26.2313 \\
\hline \multirow{3}{*}{$\mathrm{r}$} & 1050 & 91 & 5 & 87281.25 & 16.63 & 512695.3 & 578120.3 & 115624.1 & 5.00182 \\
\hline & 1040 & 93 & 5 & 86450.00 & 16.63 & 507812.5 & 572612.5 & 114522.5 & 4.00146 \\
\hline & 1060 & 96 & 5 & 88112.50 & 16.63 & 517578.1 & 583628.1 & 116725.6 & 78.7996 \\
\hline \multirow{3}{*}{ c } & 105 & 77 & 4 & 44000 & 11.00 & 200000.0 & 239800.0 & 59950.0 & 56.4460 \\
\hline & 90 & 98 & 7 & 221375 & 31.63 & 1875781 & 1998081.0 & 285440.2 & 262.904 \\
\hline & 110 & 100 & 3 & 19875 & 6.63 & 63281.25 & 85581.25 & 28527.08 & 84.4562 \\
\hline & 120 & 142 & 4 & 44000 & 11.00 & 200000 & 239800.0 & 59950.0 & 56.4460 \\
\hline & 122 & 93 & 4.4 & 57640 & 13.1 & 292820 & 341020 & 77504.55 & 38.0618 \\
\hline & 115 & 94 & 3 & 19875 & 6.63 & 63281.25 & 85581.25 & 28527.08 & 84.4562 \\
\hline
\end{tabular}


VII. CONCLUSION

In this model, a traditional EOQ model is introduced which investigates the optimal order quantity assumes that the inventory conditions govern the item stocked for general case. This model provides a useful property for finding the optimal profit and ordering quantity where the deteriorated units are not lost. A mathematical EOQ model is developed and satisfied the properties numerically. The economic order quantity and the net profit for the present model were found to be optimum respectively. Further, a numerical example is presented to illustrate the theoretical results, and some observations are obtained from sensitivity analyses with respect to the major parameters to draw the managerial implications. The model in this study is a general framework in crisp decision space.

In the future study, it is hoped to further incorporate the proposed models into several situations such as shortages are allowed and the consideration of multi-item problem. Furthermore, it may also take partial backlogging into account when determining the optimal replenishment policy. There are many scopes in extending the present work as a future research work. Parameters and decision variables can be considered random or even fuzzy. Effect of shortage, backlogging inflation etc could be added to the multi-item model. The current work can be extended in order to incorporate the modified model with shortages are allowed and the consideration of multi-item problem. A further issue that is worth exploring is that of partial backlogging. Finally, few additional aspects that the near future are the applying dynamic pricing strategy are intended through a new optimization model and stochastically of the quality of the products.

\section{REFERENCES}

[1] Bose, S., Goswami, A. and Chaudhuri, K.S. "An EOQ model for deteriorating items with linear timedependent demand rate and shortages under inflation and time discounting". Journal of Operational Research Society, 46: 775-782, 1995.

[2] Goyal, S.K. and Gunasekaran, A. "An integrated production-inventory-marketing model for deteriorating items". Computers and Industrial Engineering, 28: 755-762, 1995.

[3] Gupta, D. and Gerchak, Y. "Joint product durability and lot sizing models". European Journal of Operational Research, 84: 371-384, 1995.

[4] Hariga, M. "Economic analysis of dynamic inventory models with non-stationary costs and demand".
International Journal of Production Economics, 36: 255-266, 1994.

[5] Hariga, M. "An EOQ model for deteriorating items with shortages and time-varying demand". Journal of Operational Research Society, 46: 398-404, 1995.

[6] Hariga, M. "An EOQ model for deteriorating items with time-varying demand". Journal of Operational Research Society, 47: 1228-1246, 1996.

[7] Jain, K. and Silver, E. "A lot sizing for a product subject to obsolescence or perishability". European Journal of Operational Research, 75: 287-295, 1994.

[8] Mishra, V.K. "Inventory model for time dependent holding cost and deterioration with salvage value and shortages". The Journal of Mathematics and Computer Science, 4(1): 37-47, 2012.

[9] Osteryoung, J.S., Mc Carty, D.E. and Reinhart, W.L. "Use of EOQ models for inventory analysis". Production and Inventory Management, $3^{\text {rd }}$ Qtr: 39-45, 1986.

[10] Padmanabhan, G. and Vrat, P. "EOQ models for perishable items under stock dependent selling rate". European Journal of Operational Research, 86: 281292, 1995.

[11] Pattnaik, M. "An entropic order quantity (EnOQ) model under instant deterioration of perishable items with price discounts". International Mathematical Forum, 5(52): 2581-2590, 2010.

[12] Pattnaik, M. "A note on non linear optimal inventory policy involving instant deterioration of perishable items with price discounts". The Journal of Mathematics and Computer Science, 3(2): 145-155, 2011.

[13] Pattnaik, M. "Decision-making for a single item EOQ model with demand-dependent unit cost and dynamic setup cost". The Journal of Mathematics and Computer Science, 3(4): 390-395, 2011.

[14] Pattnaik, M. "Entropic order quantity (EnOQ) model under cash discounts". Thailand Statistician Journal, 9(2): 129-141, 2011.

[15]Pattnaik, M. "A note on non linear profitmaximization entropic order quantity (EnOQ) model for deteriorating items with stock dependent demand rate". Operations and Supply Chain Management, 5(2): 97-102, 2012.

[16] Pattnaik, M. "An EOQ model for perishable items with constant demand and instant Deterioration". Decision, 39(1): 55-61, 2012.

[17] Pattnaik, M. "Models of Inventory Control". Lambart Academic Publishing Company, Germany, 2012. 
[18] Pattnaik, M. "The effect of promotion in fuzzy optimal replenishment model with units lost due to deterioration". International Journal of Management Science and Engineering Management, 7(4): 303-311, 2012.

[19] Pattnaik, M. "Fuzzy NLP for a Single Item EOQ Model with Demand - Dependent Unit Price and Variable Setup Cost". World Journal of Modeling and Simulations, 9(1): 74-80, 2013.

[20] Pattnaik, M. "Linear programming problems in fuzzy environment: the post optimal analyses". Journal of Uncertain Systems, in press, 2013.

[21]Pattnaik, M. "Wasting of percentage on-hand inventory of an instantaneous economic order quantity model due to deterioration". The Journal of Mathematics and Computer Science, 7: 154-159, 2013.

[22] Raafat, F. "Survey of literature on continuously deteriorating inventory models". Journal of Operational Research Society, 42: 89-94, 1991.

[23] Roy, T.K. and Maiti, M. "A Fuzzy EOQ model with demand dependent unit cost under limited storage capacity". European Journal of Operational Research, 99: 425 - 432, 1997.

[24] Salameh, M.K., Jaber, M.Y. and Noueihed, N. "Effect of deteriorating items on the instantaneous replenishment model". Production Planning and Control, 10(2): 175-180, 1993.

[25] Tripathy, P.K., Pattnaik, M. and Tripathy, P.K. "Optimal EOQ Model for Deteriorating Items with Promotional Effort Cost". American Journal of Operations Research, 2(2): 260-265, 2012.

[26] Tripathy, P.K., Pattnaik, M. and Tripathy, P.K. “A Decision-Making Framework for a Single Item EOQ Model with Two Constraints". Thailand Statistician Journal, 11(1): 67-76, 2013.

[27] Tsao, Y.C. and Sheen, G.J. "Dynamic pricing, promotion and replenishment policies for a deteriorating item under permissible delay in payment". Computers and Operations Research, 35: 3562-3580, 2008.

[28] Waters, C.D.J. "Inventory Control and Management". (Chichester: Wiley), 1994.

[29] Wee, H.M. "Economic Production lot size model for deteriorating items with partial back-ordering". Computers and Industrial Engineering, 24: 449-458, 1993. 